\section{A Socioeducação como Dispositivo de Poder Disciplinar: Histórias Vividas}

\author{
Tatiane Alves de Melo e Eloísio Moulin de Souza
}

\section{RESUMO}

O objetivo deste artigo é analisar a socioeducação como dispositivo de poder disciplinar. Para cumprir seu intento, foi preciso analisar as histórias de vida de um ex-interno do Sistema Socioeducativo da região sudeste do Brasil, considerando a medida socioeducativa de internação. O estudo de cunho qualitativo adotou o método biográfico com um sujeito do sexo masculino. Na operacionalização da fase produção de dados realizaram-se encontros e conversas que oportunizaram entrevistas em profundidade. As histórias relatadas foram analisadas por meio da técnica de análise de conteúdo, criando duas categorias a posteriori. Conclui-se que a socioeducação é um dispositivo, pois inscreve-se num jogo de poder, articula estratégias de relações de forças e produz um discurso que estabelece regras de conduta para gerir a vida dos socioeducandos. A socioeducação desvela-se como um dispositivo que faz circular por inteiro o poder disciplinar, que se expressa por meio de elementos/instrumentos, como a sanção normalizadora, a disciplina, o quadriculamento, o exame, a vigilância, o olhar hierárquico e o saber gerado sobre o indivíduo, por exemplo. Os espaços socioeducativos são vigiados em sua totalidade, assim, o socioeducando é inserido meticulosamente para ser localizado, controlado, examinado, distribuído, dócil e útil.

Palavras-chave: prisão; dispositivo; socioeducação; poder disciplinar; história de vida.

The socio-educational as disciplinary power mechanism: lived stories

\section{ABSTRACT}

The objective of this article is to analyze the socioeducation as a device of disciplinary power. To fulfill its purpose, it was necessary to analyze the life stories of a former inmate from the socioeducational system in the Southeastern region of Brazil, considering the socioeducational measures of internalization. The qualitative nature of the study adopted the biographical method with a male subject. In the process of the data production phase, meetings and conversations were held, which provided in-depth interviews. The stories reported were analyzed using content analysis technique, creating two subsequent categories. It is concluded that the socioeducation is a device, therefore, it is part of a power game, articulating power relation strategies and produce a discourse that has rules of conduct for managing the lives of inmates. The socioeducation is a device that circulates a disciplinary power, which is expressed through elements / instruments, such as the normalizing sanction, discipline, squaring up, examination, surveillance, hierarchical look and knowledge generated on the individual. The socio-educational spaces are watched in their entirety, so the inmate is meticulously inserted to be located, controlled, examined, distributed, docile and useful.

Keywords: prison; mechanism; socio-education, disciplinary power; life stories.

Recebido em: 14/05/2018 Revisado em: 24/07/2018 Aprovado em: 17/09/2018

Check for updates

Tatiane Alves de Melo (iD, Instituto Federal de Brasilia - IFB, Brasil Mestre em Administração

Universidade Federal do Espírito Santo, Brasil

tatiane.melo@ifb.edu.br

\section{Eloísio Moulin de} Souza (iD,

Programa de Pós-Graduação em Administração, Universidade Federal do Espírito Santo, Brasil Pós-doutor em Administração University of Leicester

eloisiomoulin@gmail.com 


\section{Introdução}

Por razões inerentes à sua história de subordinação à estrutura de dominação globalizante, ou seja, relações de âmbito econômico internacional e progresso nos tempos da industrialização, a sociedade brasileira está assinalada por discrepâncias sociais aceleradas e pela miséria de massa que ao se pactuarem, sustentam o crescimento implacável da violência criminal, reduzida em singular flagelação das principais capitais (Wacquant, 2011). Alimentada por intensa desigualdade e pobreza, a violência ramifica-se na sociedade penal brasileira. Destarte, as discriminações hierárquicas, étnicas e raciais retratam inúmeros processos judiciais e privação de liberdade (Wacquant, 2008).

A impetuosa força policial e a condição caótica do sistema prisional se pactuam na implantação do aparato penal no Brasil, fórmula infalível para a desordem e o desrespeito à lei (Wacquant, 2008), que transgride costumeiramente os princípios e valores que está incumbida de ensinar e defender (Wacquant, 2012). No entanto, hoje ainda se esperam efeitos milagrosos dos princípios fundamentais universais da condição penitenciária, dentre eles, a educação do detento, que aos olhos do poder público é vista como perda de tempo e dispensável aos interesses da sociedade (Foucault, 1979, 2013).

Nesse aspecto, no aparelho judiciário brasileiro encontra-se a socioeducação. De tal modo, o recorte para o presente estudo é a socioeducação a partir da execução da medida de internação, isto é, a privação de liberdade para adolescentes que cometeram ato infracional, vivenciada em uma Unidade de Atendimento Socioeducativo (Almeida \& Mansano, 2012; Lei n. 8.069, 1990; Maraschin \& Raniere, 2011). Nesse sentido, a internação equipara-se à prisão, pois o adolescente infrator encontra-se segregado do convívio familiar e social no período de seis meses a três anos (Baquero, Lemes, \& Santos, 2011), afirmando-se como um tratamento tutelar realizado pelo Estado para privar o adolescente desviante do convívio social.

O objetivo geral do presente artigo é analisar a socioeducação como dispositivo de poder disciplinar, ou seja, pretende-se entender a atuação da socioeducação ao classificar, ordenar, esquadrinhar, examinar, gerar saberes e produzir vigilância. Antes de tudo, deve-se ressaltar que a socioeducação é um processo de (re)construção de projetos de vida dos adolescentes que cometeram atos infracionais e está prevista no Estatuto da Criança e do Adolescente - ECA (Lei n. 8.069, 1990). Assim, o adolescente em cumprimento de medida é vinculado ao programa socioeducativo e passa a ser acompanhado judicialmente. Além disso, cabe sublinhar que a socioeducação refere-se ao cumprimento de uma medida socioeducativa e não deve ser confundida com educação escolar e/ou educação profissional (Guralh, 2010). Ademais, a execução da medida socioeducativa de internação para adolescentes que cometeram ato infracional limita alguns direitos individuais, como o direito à liberdade e a sujeição a uma legislação especial que dispõe implicações jurídicas para a conduta transgressora (Guralh, 2010; Lei n. 8.069, 1990). 
A socioeducação brasileira reflete a realidade prisional do país (Espíndula \& Santos, 2004), tal como o descrédito quanto à ressocialização e adoção de práticas baseadas em castigo e punição (Monte, Sampaio, Rosa \& Barbosa, 2011); e uma superlotação carcerária com consequente déficit de vagas (Pires \& Palassi, 2008); acompanhados de alto custo social e econômico, criminalidade e corrupção (Cruz, Souza \& Batitucci, 2013). Nesse sentido, a temática socioeducação como objeto de estudo torna-se imprescindível e ainda tem muito que avançar, pois as instituições socioeducativas apresentam altas taxas de reincidência e ineficiência no atendimento aos adolescentes infratores (Monte \& Sampaio, 2012).

Vale salientar que, principalmente em relação ao entendimento da socioeducação como dispositivo de poder disciplinar que organiza a vida em sociedade e produz o sujeito delinquente, os estudos organizacionais brasileiros ainda têm muito que desenvolver-se, pois apresenta carência de estudos e lacunas apontadas por: necessidade de se (re)pensar o prisional e oportunizar aos internos uma convivência penal que os desprenda do crime (Costa \& Bratkowski, 2007); reconhecimento dos apenados como donos de uma história singular e não meramente como criminosos (Lemos, Mazzilli \& Klering, 1998); violação dos direitos e funcionamento dos espaços socioeducativos de internação como mini-presídio e depósito dos socialmente marginalizados (Monte \& Sampaio, 2012); atuação ineficiente de prevenção, controle e contenção dos episódios de criminalidade e violência no Brasil (Cruz \& Batitucci, 2007). Além disso, há ainda poucos trabalhos sobre o foco no desviante e formas de controle estabelecidas (Barros, 2005) e sobre aspectos disciplinares e punitivos (Almeida \& Mansano, 2012).

Outrossim, os estudos em organizações prisionais e socioeducativas provocam a produção de conhecimento e estimulam um novo olhar no campo da Administração, diferenciando-se do viés que visa a máxima da lucratividade (Silva \& Saraiva, 2013). A pesquisa que nos propusemos a executar possuiu, além disso, a pertinência de responder a demanda apresentada por Baquero, Lemes e Santos (2011) e Barros, Barros e Faria (2015) que apontam a necessidade de estudos a partir das histórias de vida dos sujeitos que vivenciaram experiências em espaços de privação de liberdade. Ademais, Silva e Saraiva (2013, p.399) elucidam que a "Administração é, sim, uma ciência social aplicada, mas não apenas para resolver os problemas das empresas, mas da sociedade"; portanto, asseguram lacunas de estudos no campo organizacional de privação de liberdade na vida social.

Em função do exposto, o artigo será assim organizado: primeiramente serão apresentados os principais conceitos relacionados ao dispositivo socioeducação, bem como poder, punição, disciplina e indivíduo objeto-sujeito, os quais têm relação com o objetivo deste artigo. Posteriormente, apresentaremos os caminhos percorridos para se realizar este estudo. Por fim, são expostas as análises sobre duas categorias: "instrumentais: olhar hierárquico e sanção normalizadora"; e "exame e o saber gerado sobre o indivíduo", que foram identificadas a partir das histórias de vida do sujeito pesquisado; seguidas das principais considerações. 


\section{O Dispositivo Socioeducação}

Ratificada por fundamentos psicológicos, pedagógicos, sociológicos, filosóficos, jurídicos e políticos, a socioeducação pode ser entendida como um processo de (re)construção de projetos de vida dos adolescentes que cometeram atos infracionais (Lei n. 8.069, 1990). Por artifício de um conjunto de ações - governamentais, não-governamentais, da União, dos Estados, do Distrito Federal e dos Municípios - a política de atendimento dos direitos da criança e do adolescente visa regulamentar o atendimento ao adolescente em cumprimento de medida socioeducativa nos diferentes âmbitos institucionais (Almeida \& Mansano, 2012; Lei n. 8.069, 1990).

Segundo Díaz (2006) a socioeducação alicerça-se também na normativa legislativa internacional, a qual é pautada na Figura 1.

\begin{tabular}{|c|l|}
\hline Ano & \multicolumn{1}{|c|}{ Normativa Legislativa Internacional que trata os direitos do homem e dos menores } \\
\hline 1924 & Primeira Declaração dos Direitos da Criança - Declaração de Genebra \\
\hline 1948 & Declaração Universal dos Direitos Humanos - aprovada pela Assembleia Geral da ONU \\
\hline 1959 & Declaração dos Direitos da Criança aprovada pela Assembleia Geral da ONU \\
\hline 1989 & $\begin{array}{l}\text { Convenção dos Direitos da Infância - aprovada pelas Nações Unidas em } 1989 \text { (reúne e integra os princípios compreendidos } \\
\text { na Declaração dos Direitos da Criança) }\end{array}$ \\
\hline
\end{tabular}

Figura 1. Normativa Legislativa Internacional

Fonte: Autores do Trabalho

Em relação ao histórico do cenário nacional da Socioeducação no Brasil, Monte e Sampaio (2012) e Almeida e Mansano (2012) discutem cronologia apresentada na Figura 2.

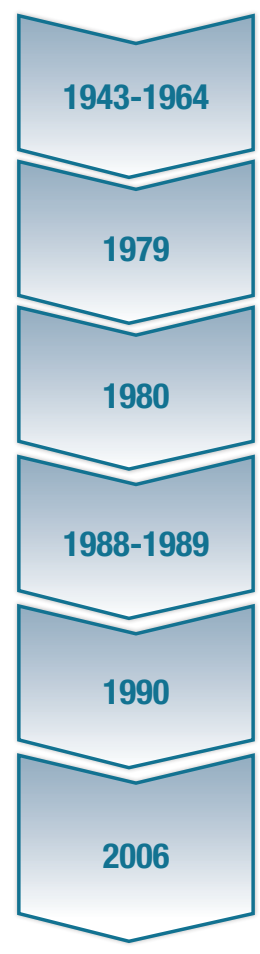

- Criação do Serviço de Assistência ao Menor (SAM) em 1943;

- Regime Militar em 1964 institui a Lei Federal 4.513 de 01 de dezembro: ciração da Fundação Nacional do Bem Estar do Menor (FUNABEM) e das Fundações Estaduais do Bem-Estar do Menor (FEBEMs).

- Revisão e reformulação do Código de Menores - que não perdeu a ideia de repressão e autoritarismo.

- Anos 80 marcaram a abertura política, redemocratização, execução de projetos pelo Fundo das Nações Unidas para a Infância (UNICEF) e da Pastoral do Menor com o apoio da Igreja Católica.

- Constituição Federal em 1988

- Convenção Internacional dos Direitos da Criança em 1989.

Figura 2. Marco histórico que rememora a Socioeducação no Brasil

Fonte: Autores do Trabalho.

- Com a consolidação da democracia, em meados de 1990 ocorre a promulgação do Estatuto da Criança e do Adolescente (ECA) implantando a Doutrina da Proteção Integral.

- Sistema Nacional de Atendimento Socioeducativo (SINASE)

- Sistema Único da Assistência Social (SUAS).

- Sistema Educacional, o Sistema Único de Saúde (SUS).

- Sistema de Justiça e Segurança Pública para o atendimento e inclusão do adolescente em cumprimento de medida. 
Nesse contexto, Maraschin e Raniere (2011) evidenciam a socioeducação como uma proposta que remete à ideia de ruptura do código de menores em relação à garantia de direitos estabelecida em 1990, com a promulgação do Estatuto da Criança e do Adolescente (ECA). É válido sublinhar as contribuições de Guralh (2010), ao elucidar que embora o termo "prática educativa" pressupõe eminentemente um direcionamento à convivência em sociedade, sendo assim, a socioeducação diferencia-se da educação escolar e educação profissional, pois configura-se como instrumento de formação para convivência social no âmbito da execução de medidas socioeducativas. Portanto, a socioeducação diferencia-se pelo contexto social em que se desenvolve a prática educativa através de diversas óticas e abordagens, como a pedagogia, a psicologia e a sociologia por exemplo, as quais atendem conjuntamente aos parâmetros para a execução da socioeducação ou trabalho socioeducativo (Guralh, 2010).

Apoiados no Estatuto da Criança e do Adolescente (ECA), baseado na Lei 8.069 de 13 de julho de 1990 (Lei n. 8.069, 1990), em relação ao cometimento de atos infracionais e resultante responsabilização dos autores - adolescentes infratores - destaca-se o artigo 112 do Estatuto da Criança e do Adolescente, que estabelece medidas aplicáveis pela autoridade competente, tais como: uma advertência, a obrigação de reparar o dano, a prestação de serviços à comunidade (PSC), a liberdade assistida (LA) ou internação em estabelecimento educacional (Almeida \& Mansano, 2012).

Desse modo, a socioeducação como dispositivo de poder disciplinar (proposta deste estudo) refere-se ao cumprimento de medida de internação em estabelecimento educacional. É válido salientar que a medida socioeducativa de internação está prevista nos artigos 112 e 121 a 125 do Estatuto da Criança e do Adolescente; sua determinação é de responsabilidade dos juízes da infância e da juventude, assim como dos adolescentes autores de atos infracionais, sendo que o período máximo de internação não pode ultrapassar três anos (Lei n. 8.069, 1990).

Além da contextualização histórica e observação de bases legais nacionais socioeducativas, a presente discussão sublinha que a socioeducação oportuniza a construção de um saber sobre os indivíduos que estão (ou estiveram) em cumprimento de medida socioeducativa de internação. De tal modo, Silva e Guedes (2011) entendem que a biografia, expressões, expectativas e anseios que são examinados por diferentes profissionais da instituição resultam no alcance de um saber individualizado; oriundos das observações, registros, análises e classificações (Jesus, 2013). Nesse sentido, a socioeducação revela-se como um dispositivo e, para o presente estudo, adota contribuições de Foucault (1979), ao esclarecer que o termo dispositivo é um conjunto heterogêneo - instituições, medidas administrativas, discursos, enunciados científicos, decisões regulamentares, organizações arquitetônicas, leis, proposições filosóficas, morais, filantrópicas - que têm por elementos o dito e o não dito.

Segundo Foucault (1979) os dispositivos são estratégias de relações de forças que sustentam e condicionam saberes, organizando-se e se inscrevendo num jogo de poder. Destarte, Foucault (1979) aponta os elementos para se afirmar um dispositivo: (1) estar inscrito em um jogo 
de poder; (2) articular estratégias de relações de forças que (3) sustentam disposições de saber. Evidencia-se ainda que os poderes que produzem e são produzidos pelo dispositivo não estão localizados em nenhum ponto particular da estrutura social, pois eles operam de modo microfísico feito uma rede de dispositivos que a ninguém escapa (Foucault, 1979; Souza, Leite-Da-Silva \& Carrieri, 2012). Nesse sentido, os dispositivos produzem discursos e regulam certas regras de condutas na sociedade (Souza \& Bianco, 2011); referindo-se às práticas sociais, as experiências cotidianas, ao modo de ser e agir do sujeito, constituído culturalmente e socialmente (Souza, Machado, \& Bianco, 2008).

Portanto, as relações poder-saber produzem simultaneamente as categorias de cidadãos ditos normais (Souza, 2014), tal como criminosos vistos como anormais. Ademais, o dispositivo socioeducação produz um discurso e consegue estabelecer regras de conduta (Souza \& Bianco, 2011), consegue demarcar (Souza, 2014) e apreender práticas discursivas e não discursivas (Souza et al., 2008). Nesse sentido, o dispositivo socioeducação cria subjetividades e busca organizar a vida social, consertar os desviantes e apontar o caminho que não comporta infrações e delitos. Portanto, a socioeducação faz circular saberes e poderes, gerindo a vida dos socioeducandos, produzindo categorização social e funções políticas; e para tal, utiliza-se do encarceramento penal, que Foucault (2013) traduz como aparelho disciplinar que priva a liberdade e objetiva a transformação os indivíduos. Assim, nos próximos tópicos discutiremos alguns conceitos sobre o poder, punição, disciplina e o indivíduo objeto-sujeito.

\section{Poder, Punição e Disciplina}

O final do século XVIII e início do XIX são marcados por processos de eliminação do espetáculo punitivo e ofuscamento do cerimonial da pena, transformado em ato administrativo. Para Foucault (2013), deixar em cartaz a cena da punição fortalecia os papéis de um judiciário assassino em relação ao supliciado objeto de piedade admirado pelos espectadores. Logo, a punição torna-se a parte mais oculta do processo penal, propagando a ideia de que a justiça não se glorifica ao impor sua força; ao contrário, tal exercício Ihe obriga a tolerância e imposição. Ademais, ter certeza de ser punido seria razão suficiente para desviar o homem do caminho do crime, sem a necessidade de suplícios em abomináveis apresentações (Foucault, 2013). Destarte, a mecânica punição substitui a dor do corpo por suspensão de direitos e supressão de liberdade, seguindo regras, nomeando guardas, psicólogos, educadores, médicos e outros técnicos que acompanham o corpo do condenado (Foucault, 2013; Garland, 2008). Esse corpo é envolvido por relações de poder e saber, preso e inserido num sistema de sujeição, tornando-se força útil na medida em que é submisso e produtivo (Foucault, 2013).

Foucault (1979) entende que os saberes sobre o corpo, por exemplo, são resultantes deumpoderconstituídoatravés do conjunto dedisciplinasescolares e militares, tal como os saberes fisiológicos e orgânicos. Compreende-se que o poder não se dá, nem se troca e tão pouco se retoma, mas se exerce 
a partir de uma relação de forças (Foucault, 1979). Segundo Foucault (1979, 2013), tal relação de poder está imbricada à produção de saber, utilizando o corpo condenado como objeto e referência de saber e, consequentemente, efeitos de poder. É válido ressaltar o processo de transição da figura do carrasco e do supliciante em praça pública para uma nova teoria jurídica que penaliza. Assim, a teoria da penalidade é a nova economia política que legitima o poder de punir, ou seja, a justiça criminal almeja maior vigilância penal atenta ao corpo social. Foucault (2013) infere que nasce uma estratégia em prol do exercício de punir e universalizar o poder de castigar. A justiça instrumentaliza-se, acompanhada por um órgão de vigilância (polícia) que visa prender autores dos crimes ou impedir o acontecimento dos mesmos; de mãos dadas, polícia e justiça se complementam.

De acordo com Foucault (2004), as relações de poder expandem-se significativamente nas relações humanas. Logo, um conjunto de relações de poder atua entre os indivíduos, por exemplo, no seio familiar, nas relações de aprendizagem escolar, no corpo político. Nesse sentido, Foucault (2003) aponta que diferentes mecanismos de poder atuam entre nós e em nossa sociedade, por meio de nossos corpos, condutas cotidianas, comportamentos sexuais, desejo, discursos científicos e teóricos que se ligam a diversos sistemas de poder, que estão ligados entre si. Assim, as relações de poder são múltiplas relações em atividade (Souza, Corvino, \& Lopes, 2013). O corpo humano como força de produção, por exemplo, existe por meio de um sistema político, que cede espaço ao indivíduo para agir, se comportar, se adaptar de maneira particular, trabalhar, sentar, andar (Foucault, 2003). De tal modo, Foucault (1979) e Fonseca (2011) corroboram com o entendimento de que a noção de poder enquanto relação de forças produtivas conduz à admissão da propagação e da capilaridade por elas alcançadas, visto que fabrica discursos, atos e pensamentos, isto é, referese às realidades ínfimas e reais do dia a dia dos indivíduos, das relações de poder conhecidas como micropoderes.

Nesse contexto, é válido sublinhar a figura do Panóptico de Bentham. Para Foucault (2003), ao final do século XVIII, organizou-se um modo de poder fundamentado na inclusão de um sistema ao qual cada indivíduo era algemado à sua própria identidade, isto é, um sistema que localiza, vigia e observa ininterruptamente visando produzir sujeitos. Assim, Foucault (1979) aponta que a prisão é o único lugar que permite a manifestação do poder em estado puro, um poder moral, onde a razão justifica a punição; se roubou, matou, foi desonesto, deve ser punido. Portanto, tal mecanismo de poder utiliza-se estrategicamente do que era inconveniente (o delinquente) e agora são úteis no âmbito político e econômico do corpo social para produzir corpos dóceis e úteis (Foucault, 1979). Assim, constitui-se o poder de punir, que segundo Pavarini (2010), é tirânico e seu exercício se identifica com o poder disciplinar.

Segundo Foucault $(1979,2003,2004,2013)$, o poder disciplinar é característico da sociedade ocidental e, associado à burguesia no século XIX, é instrumento constituinte do capitalismo industrial e das sociedades modernas. Deste modo, o poder disciplinar marca as transformações ocorridas entre sociedades burguesas e as que the antecederam. Esse tipo específico de poder tem na disciplina o segredo para conduzir seus 
procedimentos e estratégias (Fonseca, 2011; Foucault, 2013). Nesse sentido, o poder (disciplinar) é resultante das diferentes práticas sociais investidas nos corpos e mecanismos de controle, portanto, é exercido no corpo social (Souza \& Costa, 2013). Assim, objetiva conduzir a vida dos indivíduos, controlando-os em suas relações, adestrando-os, tornando-os úteis e docilizados, aprimorando as faculdades humanas em prol de maximizar seu aproveitamento. Para Melossi (2003) a disciplina é a peça indispensável da maquinaria produtiva até a modernidade da punição e, segundo Foucault (2013), pode-se dizer que a disciplina se integra por relações de poder, jogo das comunicações, e aplicação de capacidades técnicas harmonizadas umas às outras.

Para Foucault (2013), condenados úteis e obedientes são produzidos pela disciplina a partir da mecânica do poder que esquadrinha, desarticula e recompõe o corpo submisso e dócil, uma vez que as disciplinas organizam (celas, fileiras), criam hierarquias e economia (tempo, gestos). Assim, a imposição de uma ordem é resultante de uma técnica de poder, um processo de saber e, aos poucos, o corpo é controlado pelo tempo disciplinar. De tal modo, olhares vigilantes, observações, treinamentos, fiscalizações e registros das instituições disciplinares conduzem uma maquinaria de controle comportamental na engrenagem do poder disciplinar (Foucault, 2013). De acordo com Foucault (2010), as disciplinas indicam diferentes modelos de articulações, como: disciplinas do tipo monástico ou penitenciário (relações de poder e de obediência), disciplinas do tipo das oficinas ou hospitais (atividades finalizadas) e disciplinas do tipo de aprendizagem (relações de comunicação).

Foucault (1979, 2003, 2004, 2013) e Fonseca (2011) apontam que as disciplinas são métodos que oportunizam um controle meticuloso do corpo, de suas partes, de forças, do tempo e das atividades. Nesse sentido, "as disciplinas têm por principal alvo o corpo" (Souza \& Costa, 2013, p.8). Segundo Fonseca (2011), seus mecanismos atendem às táticas de poder quando: o exercício deste é menos custoso, os efeitos deste são maximizados e ocorre o rendimento dos aparelhos onde este é exercido. Destarte, Foucault (2013) e Fonseca (2011) elucidam que as disciplinas são identificadas como um nexo de diferentes técnicas que são aplicadas em lugares institucionais - nunca reduzidas a tais instâncias -, e não devem ser associadas a uma instituição. Ademais, é válido ressaltar que a disciplina dispõe de três mecanismos que caracterizam o poder disciplinar (Fonseca, 2011; Foucault, 1979, 2013): (1) a vigilância, que objetiva habilitar o olhar da máquina disciplinar a uma visão absoluta e perene, ao ponto que sua efetividade transforme-o em seu próprio guardião; (2) a sanção normalizadora, ou procedimentos punitivos de menores atos e comportamentos mais sutis realizados nos lugares de execução da tecnologia disciplinar, que recai sobre a brecha deixada pelas leis; e (3) da somatória vigilância e sanção normalizadora, tem-se o exame, um meio estratégico que possibilita o investimento político sobre instituições e indivíduos; facultando a efetivação de notáveis funções disciplinares.

No entendimento de Lemos, Cardoso e Alvarez (2013), a disciplina é uma tecnologia com finalidade e funções precisas nas instituições, como prisões, escolas, casas de internação, hospitais, polícia e exército, por exemplo. De tal modo, na tecnologia disciplinar, importa primordialmente que a pluralidade 
de corpos seja limitada e o espaço não muito amplo, o que significa dizer que as instituições são, por isso, espaços disciplinares. Ademais, Fonseca (2011) entende que o efeito obtido pela punição disciplinar é entendido pela confirmação do poder da norma. No entanto, a normalização não deve ser compreendida como consequência de um método repressivo, mas como técnicas de sanções direcionadas a uma funcionalidade. Nesse contexto, é válido destacar que para Foucault $(1979,2013)$ e Fonseca (2011), o castigo define-se como um corretivo, um exercício de recondução, e não um ato vingativo - exibição de força de um poder ou de uma legislação violada.

Segundo Foucault $(1979,2013)$ e Fonseca (2011) o indispensável efeito da disciplina é a construção de aparelhos eficientes, produzindo um tipo de indivíduo, ou seja, o indivíduo moderno. Este não deve ser considerado como membro desconhecido da monstruosa massa; ao contrário, ele possui uma identidade à qual pertencem seus sinais e impressões mais profundas de corpo útil e dócil. Considera-se ainda que essas marcas se concretizam a partir da especialização (particularização) de indivíduo por indivíduo, empreendida pela disciplina, garantida a utilização do ser humano moderno. Na época da disciplina, os indivíduos são singularizados, possuindo um status: ter uma identidade; assim, a identidade carrega consigo a marca do ser útil e dócil (Fonseca, 2011; Foucault,1979, 2013). Além disso, Foucault (2013, 1979) e Fonseca (2011) apontam que na sociedade disciplinar, a prisão encarna a forma de objetivação mais depurada, pois tem em mãos uma tecnologia política do corpo. De tal modo, este corpo do indivíduo é seu fundamental lugar de aplicação (Maraschin \& Raniere, 2011), possibilitando a formação do indivíduo/objeto dócil e útil: se este não falava, agora o indivíduo/sujeito deve falar, afinal, mudo não pode ser mais; se antes tinha um condicionante de objeto que o permitia ficar mudo, na modernidade sua condicionante de sujeito, roga ser falante (Fonseca, 2011; Foucault, 1979, 2013).

\section{Indivíduo objeto-sujeito}

Segundo Souza (2014), os processos de subjetivação modelam, marcam, desmarcam e delineiam o homem constantemente, construindo sua subjetividade e identidade. Portanto, o indivíduo constitui-se sujeito "através do fluxo de forças que o passam, perpassam, transpassam, ou melhor, são estas forças que constituem o indivíduo como sujeito por meio de processos de reconhecimento e identificação em categorias" que são construídas discursivamente (Souza, 2014, p.115). De tal modo, Foucault (2012) e Souza, Petinelli-Souza e Leite-Da-Silva (2013) apontam que a forma de controle na atualidade caracteriza-se pela atuação sobre o indivíduo, pois ao controlar e fabricar, ela impõe uma identidade, uma individualidade ao sujeito. Ademais, Nardi (2006) salienta que os processos de subjetivação são compreendidos ao considerar a maneira como o indivíduo associa em seu tempo, do seu modo, ao próprio regime de verdades, pelo jeito que o conjunto de regras sociais é experienciado por ele, em sua trajetória de vida. Em suma, a aplicação política sobre a vida (nos processos de objetivação e subjetivação) é o que permite a formação do indivíduo enquanto objeto sujeito (Fonseca, 2011; Foucault, 1979, 2003, 2004, 2010, 2013). 
É válido ressaltar que pelo termo subjetividade, entende-se aquilo que é peculiar ao sujeito, algo fundamental que apoia os aspectos consideráveis da existência, que evidencia particularidades do ser humano (Nardi, 2006). Nesse sentido, a subjetividade nomeia-se nos campos da economia subjetiva e da economia sociopolítica, pois "a subjetividade é pensada como um conceito operativo, uma categoria analítica que permite a compreensão da dinâmica e da estrutura social a partir da indissociabilidade do individual e do coletivo" (Nardi, 2006, p.23). Desse modo, analisar e compreender os processos de produção de subjetividade significa o entendimento dos modos de subjetivação (Nardi, 2006).

Ademais, Foucault (2010) elucida que os processos de objetivação são entendidos como práticas que, incorporadas a nossa cultura, dispõem a transformar o homem num objeto, assim, com base nos mecanismos disciplinares, torna-se factível a constituição do indivíduo moderno, isto é, um objeto útil e dócil (Foucault, 1979, 2013). Nessa lógica, os processos de subjetivação pretendem compreender as práticas que, em nossa cultura, concebem o homem como sujeito, quer dizer, as práticas que integram o indivíduo moderno - um sujeito amarrado a uma identidade que lhe é dada como própria. Cabe ressaltar que o sujeito está preso a relações complexas de poder, pois está envolvido em relações de produção e significações (Fonseca, 2011; Foucault, 1979, 2003, 2004, 2010, 2013).

Segundo Nardi (2006), é através das experiências de vida que os sujeitos se constroem e são construídos, isto é, constituem os processos de subjetivação. Assim, "o significado atribuído à existência adquire sentido dentro de um determinado jogo de verdades próprio a cada contexto espaço-sócio-temporal" (Nardi, 2006, p.135), sendo que é impossível especificar todos os elementos imbricados neste processo. Todavia, torna-se possível nomear os dispositivos atuantes na sociedade: códigos morais, cultura, religião, família, escola e outros tipos de socialização, que conjuntamente determinam os modos de subjetivação característicos a cada contexto (Foucault, 1979, 2003, 2004, 2010, 2013; Nardi, 2006). Dessa forma, Gomide, Nogueira e Barros (2010) entendem que, ao vivenciar, experimentar, reinventar e traduzir normas/regras definidas pela sociedade, o sujeito adquire maneiras de se relacionar com determinado regime de verdades que caracterizam períodos vividos. Assim, no próximo tópico apresentaremos a metodologia utilizada para a realização deste estudo.

\section{Caminhos Percorridos}

O presente estudo consiste num trabalho de cunho qualitativo (Creswell, 2003), por meio do método biográfico (Barros \& Lopes, 2014). Herdeira da Escola de Chicago, a abordagem biográfica é uma sociologia que se caracteriza pela pesquisa empírica, que valoriza o trabalho de campo como uma prática corrente (Barros \& Lopes, 2014; Barros \& Silva, 2002; Gomide, Nogueira, \& Barros, 2010). Desse modo, não existe uma receita que deve ser seguida para recolher uma história de vida, no entanto, considera-se a singularidade de cada história e o caminho para compreender tal universo (Barros \& Lopes, 2014). Assim, a proposta metodológica escolhida 
fundamenta-se numa perspectiva dialógica (recolhimento em história de vida), que valoriza a fala, a escuta, a troca, a reflexão sobre a trajetória do sujeito entrevistado, oportunizando não somente o entendimento do vivido social - maneiras de negociar em diferentes circunstâncias -, mas, apreendendo saberes ao ultrapassar limites das sapiências disciplinares (Barros \& Silva, 2002; Gomide et al., 2010). Para Lévy (2000) o método da abordagem biográfica possibilita um caminho para acessar processos que sustentam a sociedade e suas histórias sociais, que são subjetivamente vividas em dimensões - psicológicas, culturais, econômicas, sociais históricas e atuais.

O recolhimento em história de vida "nos mostra uma cultura, um meio social, um esquema de valores e de ideologia, uma vez que, como membro de uma família, de um grupo, de uma organização, o sujeito se encontra sempre em interação" com tais grupos (Barros, 2005, p.55). De tal modo, o presente estudo adotou o método biográfico trilhando um caminho de uma passagem na história individual, com anseio de acessar a história coletiva, o que com clareza, explicou Gaulejac, "tal uma boneca russa, a história individual está encaixada na história familiar e ela mesma inserida em uma história social” (Gaulejac, 1991, p.21). Além disso, Chauí (1979) corrobora com o entendimento de que a história de vida não deve ser compreendida como triunfo do individualismo, pois, ao recolocar o sujeito no centro da cena, tal desdobramento é o relato de todos. Significa dizer que a manifestação por meio do relato constrói e se reconstrói no campo da subjetividade, a partir do caráter individual que é construído na experiência coletiva (Chauí, 1979). Assim, Barros e Silva (2002) apontam que se trata da maneira que o sujeito elabora sua subjetividade, contando sua história, a partir do seu ponto de vista.

Intentou-se desenvolver este estudo com um sujeito do sexo masculino, ensino fundamental incompleto, ex-interno do Sistema Socioeducativo da Região Sudeste do Brasil. A escolha do sujeito de pesquisa do sexo masculino justifica-se devido à representatividade na socioeducação ser de $96 \%$ em relação ao sexo feminino, este com 4\%. Observa-se, ainda, os dados do Levantamento Anual Sinase - Sistema Nacional de Atendimento Socioeducativo - referente ao ano de 2013, no qual tem-se um número total de 15.221 adolescentes e jovens (12 a 21 anos) em restrição e privação de liberdade na modalidade socioeducação tipo internação; sendo que a Região Sudeste do Brasil detém $60,5 \%$ do total de socioeducandos internados (Brasil, 2015).

É válido sublinhar que o lócus da pesquisa dividiu-se entre os espaços: da residência do tio do sujeito de pesquisa - devido aos horários disponíveis em virtude de um trabalho temporário que o mesmo executara no período da pesquisa; da sala de uma Universidade Federal localizada na Região Sudeste do Brasil - devido ao desejo do sujeito de pesquisa em conhecer o espaço universitário; da residência do sujeito de pesquisa - a convite do mesmo. Ressalta-se que na operacionalização da fase produção de dados realizaramse encontros e conversas que oportunizaram entrevistas em profundidade, deixando o entrevistado contar as histórias de sua vida. Assim, foi possível realizar doze (12) encontros gravados em áudio, totalizando aproximadamente treze horas de gravação que posteriormente foram transcritas. 
As histórias relatadas foram analisadas por meio da técnica de análise de conteúdo, criando categorias a posteriori. Para a criação de categorias, observou-se a exclusão mútua, a pertinência, a objetividade e a fidedignidade, na busca por um conjunto de categorias produtivo (Franco, 2003). A estratégia de investigação deste artigo definiu-se como narrativa, ao solicitar que uma pessoa conte sua história de vida. A análise e categorização dos relatos foram realizadas à luz do referencial teórico, e tais informações foram recontadas e recriadas pelos pesquisadores em uma cronologia narrativa. Optou-se pela utilização de nomes fictícios para todos os envolvidos nas histórias contadas, respaldando o sigilo em relação à identidade do sujeito de pesquisa.

Interessa ainda salientar que estudar as histórias de vida dos sujeitos que vivenciaram experiências em prisões não se resume em simples interesse pela história pessoal, mas, especialmente pela oportunidade de compreender situações do inexplorado universo social prisional e socioeducativo (Barros, Barros, \& Faria, 2015). Portanto, por meio da utilização do método biográfico é possível analisar e compreender os fenômenos sociais mais amplos (Abrantes, 2012). Desse modo, serão apresentadas algumas análises gerais sobre a história de vida em questão, de acordo com os elementos que surgiram dessa própria narrativa. Contudo, a ênfase será a socioeducação como dispositivo de poder disciplinar, tema deste estudo. Assim, os próximos tópicos estão organizados de acordo com duas categorias encontradas a posteriori: "instrumentais: olhar hierárquico e sanção normalizadora"; e "exame e o saber gerado sobre o indivíduo".

\section{Dispositivo de Poder Disciplinar: Socioeducação}

No espaço que se segue, trouxemos a análise das histórias recolhidas a partir dos encontros com o sujeito de pesquisa. São vários relatos contando da vida, principalmente durante o período de internação socioeducativa. Primeiramente começaremos a analisar a categoria nominada "instrumentais: olhar hierárquico e sanção normalizadora", para em seguida abordar a segunda categoria identificada como "exame e o saber gerado sobre o indivíduo".

\section{Instrumentais: olhar hierárquico e sanção normalizadora}

Segundo Foucault (2013) castigar o corpo não requer mais plateia, dor e sofrimento físico como na época dos suplícios, pois, a partir do século XVIII as regras e normalizações substituem a cerimônia punitiva. Nesse sentido, as histórias relatadas pelo sujeito de pesquisa [Felipe] corroboram com contribuições acerca da disciplina (Fonseca, 2011; Foucault, 1979, 2010, 2013; Lemos et al., 2013; Melossi, 2003; Souza \& Costa, 2013), como: "trinta dia dentro de uma cela, de manhã eles tiravam meu colchão, tirava o chinelo, pra num bater chapão, e cê ficava ali, sentado naquela pedra ali, olhando pras parede, olhando pra grade ali. Tinha os horários pra comer, tomar banho, jantar" (Felipe). Desse modo, Foucault (2013) aponta que ao isolar o indivíduo, retirar as possibilidades de distração, limitar o acesso à 
família e reduzir a prática de atividades, o dispositivo socioeducação dispara estratégias que constroem os sujeitos a partir das relações de poder no processo socioeducativo. Foucault (2013, p.223) entende que o isolamento dos "condenados garante que se possa exercer sobre eles, com o máximo de intensidade, um poder que não será abalado por nenhuma outra influência; a solidão é a condição primeira da submissão total”, pois o isolamento atesta o encontro do interno com o poder que é exercido nele e circula no nível social, esquadrinhando, separando e classificando.

"Cê chegava no especializado ali, e ficava ali uns dias ali, dentro daquela tranca lá" (Felipe). Dias na tranca, dias sozinho. É desse modo que se isola o condenado do mundo exterior, segundo Foucault (2013). A ideia é isolar de tudo que motivou o cometimento do ato infracional, isolar dos outros e fazer a pena individualizante. Nesse sentido, as técnicas do poder disciplinar descritas por Foucault (2013), como as sanções normalizadoras e disciplinas, ratificam-se por meio das histórias vividas por Felipe ao ser acautelado [novamente] após descumprir as regras/normas da instituição de internação. Entende-se que acautelar o jovem Felipe no atendimento especializado durante trinta dias foi a punição que o diretor estabeleceu para a infração cometida, pela regra violada, o que significa privá-lo do convívio com outros internos [servir de exemplo], aumentar o tempo que se passa dentro da cela e reduzir o tempo para receber visitas. Ele foi condicionado, submetido às disciplinas do Centro de Internação (Cl) e, segundo Foucault (2013, p.133), são estes "métodos que permitem o controle minucioso das operações do corpo, que realizam a sujeição constante de suas forças e Ihes impõem uma relação de docilidadeutilidade", descritas abaixo por Felipe:

\footnotetext{
Pra andar de um lugar pra outro lá dentro da Unidade era de cabeça baixa, mão pra trais, uniforme pra dentro, não podia olhar pra cara de ninguém. Andar na fila, andar no famoso procedimento que eles falava né? Procedimento é revista, a tal da revista minuciosa, é você tirar a roupa e se humilhar pra eles né?! Eles cobrava muito, tinha leis, tinha regras que cê tinha que seguir, eu achei que eles tavam mandando nim mim, entende?
}

Foucault (2013) corrobora com o entendimento da "disciplina" como uma técnica que consegue fabricar os indivíduos, transformando-os em instrumentos e objetos do exercício de poder que modestamente operam em meio a uma economia deliberada e permanente. Cabe sublinhar que a família cumpre medida socioeducativa com o socioeducando, pois também está sujeita às atividades descritas na jornada pedagógica, reuniões/intervenções com a equipe técnica, visitas domiciliares do serviço social, participar das cerimônias e eventos comemorativos. Além disso, a família deve obedecer às regras, normas e procedimentos: "a revista da família era mema coisa da nossa revista que nois fazia, então eu me sentia desconfortável, pra minha mãe, pra todo mundo da família que ia visitar. Era revista minuciosa pra todo mundo" (Felipe). A família deve ser corpo útil e dócil, tal como o socioeducando. Nesse contexto, ao julgar a maneira da disciplina que recebia, Felipe reclama também da postura dos agentes socioeducativos de segurança e afirma que "percebia assim, cê percebia, o deboche num tem? Às vezes eu ia falar alguma coisa e acabava sendo avaliado? E lá quem tinha mais razão, na maioria das vez era os agente, né?". 
De tal modo, Foucault (2004, p.275) considera que o sujeito delinquente é constituído por diferentes formas que são definidas a partir de práticas de poder e jogos de verdade, "isso significa que o sujeito não é uma substância... Não é uma substância. É uma forma, e essa forma nem sempre é, sobretudo, idêntica a si mesma". Assim, tanto Foucault (2004, 2010, 2012) e Souza et al. (2013) entendem que o sujeito pode sujeitar-se a alguém ou a sua identidade por meio da consciência ou autoconhecimento. É válido ressaltar que no entendimento dos autores Maraschin e Raniere (2011), ao executar uma intervenção sobre a rotina socioeducativa, o Estado busca intervir e gerenciar o tempo dos corpos indisciplinados, com o pacto de transformação de hábitos e a busca por um corpo dócil-legal (socialmente-útil-socialmente-legalizado).

\begin{abstract}
Você tá dentro do espaço de convívio, cê tem que ficar esperto pra num tomar certa atitude e pra num ser avaliado... Questão de religião tinha um dia específico de culto, que era no sábado, quem não tivesse acautelado, trancado ia pro culto. Quem não quisesse, tinha que ir, todo mundo tinha que ir e era a maioria igreja evangélica. Eu até gostava. Mais, sempre com a realidade de frente pros olhos né, a realidade que eu tavo vivendo. Ué a realidade, muros, tranca, procedimento, agente, algema, tudo isso é realidade né mano? (Felipe)
\end{abstract}

Ao relatar algumas situações que o incomodavam no cumprimento da medida socioeducativa de internação durante o período que esteve no Centro de Internação, Felipe retrata que teve dificuldades para entrar no ritmo: "agente vim e mandando eu abaixar a cabeça, andando de mão pra trais, roupa pra dentro, eu...eu num tavo aceitando aquilo". Em meio as relações de poder exercidas no dispositivo socioeducação, observa-se os jogos estratégicos de poder, que segundo Foucault (2004) estão imbuídos de tecnologias governamentais - forma de gerir a instituição, a gestão da vida de Felipe na socioeducação. Entende-se que a relação do socioeducando com os agentes socioeducativos de segurança, por exemplo, reafirmam a visão foucaultiana, uma vez que os "jogos estratégicos fazem com que uns tentem determinar a conduta dos outros, ao que os outros tentam responder não deixando sua conduta ser determinada ou determinando em troca a conduta dos outros" (Foucault, 2004, p.285).

Por conseguinte, Foucault (2013, p.154) elucida que "o poder se articula diretamente sobre o tempo; realiza o controle dele e garante sua utilização", e no presente estudo, considera-se, por exemplo, a organização de jornadas pedagógicas que incluam atividades terapêuticas, culturais, religiosas, esportivas, psicossociais, laborais, escolares, profissionalizantes, familiares e afins. Um exemplo disso pode ser visto a partir das lembranças narradas por Felipe, em que ele diz: "trabalhar dentro da cozinha, pra mim, eu achava bom, porque eu num ficava trancado né. Eles me passava as tarefa que eu tinha que fazer, era uma distração pra mim e também eu aprendi fazer várias coisa ali". Nesse sentido, Pavarini (2010, p.191) corrobora com o entendimento de que seria "mais fácil estimular os internos ao trabalho através da expectativa de "privilégios" do que através das ameaças de "punições"”. Desse modo, "dentro da cozinha num tinha gente pra vigiar nois lá não, num ficava com aquela de agente ficar em cima de você" (Felipe), e a ênfase de Pavarini (2010) é que este trabalho produtivo permite a substituição da disciplina alicerçada na vigilância pela disciplina que minuciosamente é incorporada à organização do trabalho. 
Destarte, Felipe recorda que estava "sempre com a realidade de frente pros olhos né, a realidade que eu tavo vivendo. Ué a realidade, muros, tranca, procedimento, agente, algema, tudo isso é realidade né mano?". Isto posto, Souza et al. (2013) salientam que tal realidade o constrói e o reconstrói a partir das relações sociais, das relações de poder, do fluxo de forças e das estratégias que perpassam o dispositivo socioeducação. "Então tinha certo tempo lá que eu tentava esconder aquilo dali que eu tavo vivendo mais, a ficha caia muito rápido do que eu tavo, que eu tavo preso mesmo" (Felipe). Para Almeida e Mansano (2012), devemos considerar que os adolescentes e jovens que cumprem medida socioeducativa de internação não estão unicamente à mercê de uma proposta pedagógica. A "realidade", a "ficha que caía" das lembranças de Felipe, reforça o entendimento de Almeida e Mansano (2012, p. 180) ao explanarem que "a arquitetura institucional, com a presença de grades, as obrigações, o controle de rotina e o núcleo de convivência, por si sós, comportam características disciplinares e punitivas". Portanto, Felipe é identificado como socioeducando que precisa ser acompanhado, vigiado, controlado, docilizado, classificado, ordenado e esquadrinhado, confirmando as contribuições de Foucault (1979, 2003, 2004, 2010, 2013).

Ademais, "eu vi tipo que era uma obrigação o adolescente mudar, não tem como, na minha mente num tava de sair e fazer algumas coisas certas não, sempre disfarçando né?! Sempre dando uma de besta pra sobreviver" (Felipe). Isto segue o poder da normalização, as técnicas de sanções que operam e produzem efeito de punição disciplinar (Fonseca, 2011). Ao receber a medida socioeducativa de internação, o socioeducando torna-se sujeito em privação de liberdade e precisa seguir normas/disciplinas, agora já não decide por si só o que fazer com seu corpo e tempo. Assim, "minha mente era fingir que tava bem ali na situação pra mim ir embora. Fazia o que tinha que fazer, cumpri o que tinha que cumpri, do jeito deles né, até alcançar a rua" (Felipe). Em vista disso, esse corpo está condicionado a ser instrumento do sistema socioeducativo, entendido por Foucault (2013, p.16) como "privar o indivíduo de sua liberdade considerada ao mesmo tempo como um direito e como um bem", significando penalizá-lo e, ao mesmo tempo, alimentar a economia dos direitos que foram suspensos. Ademais, ao controlar e transformar o comportamento dos internos, Foucault (2013) compreende que se forma um saber sobre tais indivíduos. Assim, a próxima categoria identificada no presente estudo, discute o exame e o saber gerado sobre o indivíduo.

\section{Exame e o saber gerado sobre o indivíduo}

Os efeitos produzidos pela privação de liberdade reforçam o sucesso que sustenta a existência da fracassada prisão (Foucault, 2013), que é vista pela sociedade como uma resposta aos problemas sociais que envolvem a criminalidade (Barros et al., 2015). Segundo Foucault (2013), em virtude do modelo normativo de privação de liberdade, uma tropa de técnicos de diversas áreas do conhecimento, como os saberes médicos, psicológicos e jurídicos [como parte da disciplina], ocuparam o lugar do carrasco. De tal modo, com o passar dos séculos, o progresso na reforma penal objetivou aumentar o número, a atribuição, a necessidade dos especialistas sociais 
em delinquência. Para Garland (2008), a justiça criminal tornou-se território dos agentes de segurança, assistentes sociais, pedagogo(a)s, psiquiatras e outros profissionais sortidos com diferentes saberes. Nesse contexto, consideremos as histórias que o jovem Felipe relata a respeito das dificuldades para cumprir as regras do Projeto Institucional Socioeducativo (PIS) e as rotineiras avaliações com RE e/ou R que recebia da equipe. Com o passar do tempo, ele percebeu que a quantidade de avaliações que tinha em sua ficha estava aumentando o tempo de internação no Centro de Internação $(\mathrm{Cl})$ :

Cê tinha que avançar semana pra pegar outra camisa e ganhar estímulo né? Estímulos, que eles falava. Só que eu era avaliado, todos, quais todos dia eu era avaliado... Teve uma semana que eu recebi quinze $R$, quinze R's... Fiquei acautelado várias vezes... fui tentar fazer as conta, eu vi que se fosse pra mim pagar aqueles $\mathrm{R}$ tudo, e pra mim ir embora, Nossa Senhora da Penha ia ficar muito tempo ali (Felipe).

Tal afirmação pode ser entendida como estratégia do dispositivo socioeducação, que exerce o poder disciplinar ao adestrar o socioeducando, além de gerir a sua vida e controlá-lo (Souza \& Costa, 2013), pois, segundo Foucault (2013, p.164), o poder disciplinar vai "adestrar para retirar e se apropriar ainda mais e melhor. Ele não amarra as forças para reduzi-las; procura ligá-las para multiplicá-las e utilizá-las num todo". Nesse sentido, vale ressaltar que, se comparado aos rituais soberanos de punição do século XVIII, ser avaliado com RE's e R's, acautelação e ganhar mais tempo de internação seriam procedimentos modestos.

Todavia, Foucault (2013, p.164) atesta que "o sucesso do poder disciplinar se deve sem dúvida ao uso de instrumentos simples: o olhar hierárquico, a sanção normalizadora e sua combinação num procedimento que the é específico, o exame". Portanto, ao munir educadores, equipes técnicas e agentes socioeducativos de segurança com autonomia para aplicação de RE e/ou R, o dispositivo socioeducação visa disciplinar, controlar, examinar, docilizar, adestrar, produzir saberes e gerir a conduta dos socioeducandos. Nesse sentido, Felipe explica que foi necessário fazer um seminário para reduzir a quantidade de avaliações que tinha, apresentando, assim, sua história de vida para a equipe técnica e diretoria. Após responder aos questionamentos, ele conseguiu reduzir a quantidade de RE's/R's e avançou no projeto, afinal, o dispositivo socioeducação é um dispositivo de disciplina que produz vigilância, atuando por meio de técnicas e normalizações.

Foucault (2013, p.177) aponta que é o controle normalizante com vigilância que vai possibilitar a classificação, a qualificação e punição, pois, "o exame combina as técnicas da hierarquia que vigia e as da sanção que normaliza. Estabelece sobre os indivíduos uma visibilidade através da qual eles são diferenciados e sancionados". Logo, ao passar pelo atendimento especializado algumas vezes e elaborar seminários, Felipe percebeu que se ficasse tranquilo, seria examinado positivamente pela equipe e avançaria no projeto: "Ali foi caindo um pouco, caiu um pouco a ficha, que eu tavo vendo que se num ficasse tranquilo ali, num tinha jeito pra você ir embora. Cê tinha que ficar tranquilo". No entanto, Felipe expõe sua indignação em relação aos atendimentos técnicos no processo socioeducativo, exemplificando 
que, ao ser confrontado pela equipe e dizer o que realmente pensava, sentia que era punido de alguma maneira. Logo, o poder de punir é exercido pelo dispositivo socioeducação, e Foucault (2013, p. 242) admite que esse "organiza silenciosamente um campo de objetividade em que o castigo poderá funcionar em plena luz como terapêutica e a sentença se inscrever entre os discursos do saber".

Segundo Jesus (2013) a equipe técnica realiza os atendimentos e registra-os em arquivos, planilhas e relatórios que serão encaminhados para avaliação do judiciário no período máximo de seis meses. Nesse sentido, Foucault (2013) certifica que, a partir do exame, o indivíduo é incluído num terreno documentário que arquivará minuciosamente os detalhes que organizam os corpos e o passar do tempo. "Eles tinha que saber se o adolescente quer ou não né?! Se você num que ser ouvido, cê num quer falar, então tudo bem, aí é tenso" (Felipe). Ao citar a obrigatoriedade em participar dos atendimentos com a equipe técnica Felipe conta que "cê tinha que fazer, num tem? Se eles chamava, era acompanhar e pronto, num perguntava não. Tipo assim, obrigava o adolescente a gostar, era o que acontecia". De tal modo, o exame solicitado pelas disciplinas possibilita o investimento político sobre a vida das pessoas (Fonseca, 2011; Foucault 2013; Nardi, 2006). Ao ser vigiado, avaliado e examinado o socioeducando Felipe é descrito via relatórios que são elaborados pela equipe técnica e encaminhados ao judiciário que, por sua vez, tem a tarefa de avaliar tal parecer e em determinado momento expedir o alvará de soltura.

Salienta-se que, no processo socioeducativo, as relações de poderes e saberes constroem um sujeito que prefere usar a "máscara" e ser bem visto pela equipe. Ele optou por seguir o projeto e "cumprir o que tinha que cumpri” (Felipe), pois o dispositivo socioeducação tem em mãos o que enfatiza Fonseca (2011): o corpo do indivíduo, a tecnologia política que constitui a docilidade e utilidade. Nesse contexto, Foucault (2013, p.177) elucida que o exame "manifesta a sujeição dos que são percebidos como objetos e a objetivação dos que se sujeitam", apresentando o socioeducando como efeito de poderes e saberes da socioeducação. Portanto, Foucault (2013) corrobora com o entendimento de que esse conjunto de pareceres apreciativos, análises, diagnósticos, normativos, prenúncios, pertencentes ao indivíduo delinquente encontra acolhida no sistema judiciário penal, esmiuçando o sujeito delinquente recrutado, o socioeducando, o adolescente, o Felipe.

Ademais, Felipe menciona que a equipe técnica do Centro de Internação apresentou as regras e procedimentos e que "eles falava lá que nois num tava preso, nois tava cumprindo uma medida, vamo dizer, tipo querendo iludir né?! Porque a realidade é que nois tava preso memo, porque nois não tinha liberdade, não tinha liberdade". Desta maneira, a equipe técnica socioeducativa ratifica as contribuições de Foucault (2013, p.16) sobre o efeito no corpo dos justiçáveis, pois "por sua simples presença ao lado do condenado, eles cantam à justiça o louvor de que ela precisa: eles the garantem que o corpo e a dor não são os objetos últimos de sua ação punitiva", porém, tal discurso já não convence tanto os socioeducandos. Desse modo, nos encontros matinais denominados de "grupo socioterapêutico", os adolescentes eram questionados sobre "o estado de espírito" e, segundo 
Felipe, era muito comum ouvir: "só o ódio". "Quando os adolescente falava aquilo dali, tava dizendo o que tava sentindo" (Felipe), que segundo Foucault (2004, 2010) é um exercício das relações de poder, uma vez que o modo que alguns vão agir em relação aos outros é uma estratégia, uma possibilidade de resistir.

Cabe enfatizar que ao narrar sua participação nas atividades da jornada pedagógica - com ênfase nas terapias, seminários e grupos socioterapêuticos citados nos relatórios técnicos - Felipe menciona: "no lance de terapia assim, quando eu não ia, eu inventava alguma coisa, que tavo passando mal, tavo com problema, num tavo muito bem, tinha as artimanha pra driblar ali aquela situação, pra num participar, né?". Para Almeida e Mansano (2012) é um sentimento de perda de tempo, um tempo que destrói a vida e em algum momento precisa ser apagado. Por conseguinte, sublinha-se que alguns socioeducandos cumpriram a medida socioeducativa "tranquilos" obedecendo às regras, participando dos atendimentos técnicos e terapêuticos - porque perceberam que a melhor maneira de "alcançar a rua" era "fingir que tava bem" (Felipe). Nesse sentido, Foucault (2013, p.179) aponta que o poder disciplinar "se exerce tornando-se invisível: em compensação impõe aos que submete um princípio de visibilidade obrigatória".

Por fim, os autores Maraschin e Raniere (2011) entendem que ao cumprir as atividades descritas na jornada pedagógica ou programa-rotina da instituição, os socioeducandos reafirmam a crença dos socioeducadores de que é possível articular as engrenagens escolares, religiosas, profissionalizantes, culturais para reprogramar, corrigir as tendências indisciplinadas e ilegais que o levaram até a socioeducação. Ademais, o exame insere os indivíduos no terreno de vigilância, comprometendo-os por meio de documentos e registros que servem para capturá-los e fixá-los (Foucault, 2013). Além disso, devemos considerar que o mecanismo da disciplina constitui um poder de escrita que a partir do exame é capaz de identificar, assimilar, controlar e descrever o sujeito no corpo social (Foucault, 2012, 2013). Devemos entender que o estatuto da verdade que se alinha com o poderio punitivo entrelaça-se aos saberes, produzindo efeitos, informações e conhecimentos (Silva \& Saraiva, 2013).

\section{Considerações Finais}

O objetivo deste artigo foi analisar a socioeducação como dispositivo de poder disciplinar. Em vista disso, certifica-se que a socioeducação é um dispositivo, pois inscreve-se num jogo de poder, articula estratégias de relações de forças e produz um discurso que estabelece regras de conduta para gerir a vida dos socioeducandos. Desse modo, a socioeducação desvela-se como um dispositivo que faz circular por inteiro o poder disciplinar, que se expressa por meio de elementos/instrumentos, como a sanção normalizadora, a disciplina, o quadriculamento, o exame, a vigilância, o olhar hierárquico e o saber gerado sobre o indivíduo. Observa-se que os espaços socioeducativos são vigiados em sua totalidade, assim, o socioeducando é inserido meticulosamente para ser localizado, controlado, examinado, distribuído, dócil e útil. 
Consideramos que os acontecimentos se transformam em registros, além disso, a escrita e as anotações são rotineiras, constituindo um modelo denso do dispositivo disciplinar. Por ser um dispositivo, a socioeducação tem um discurso que circula e não se limita aos centros e institutos socioeducativos, o que significa dizer que a socioeducação como dispositivo está presente e atua por meio de práticas discursivas em diversos lugares da sociedade. De tal modo, a socioeducação produz saberes e poderes, criando subjetividades e organizando a vida social, visando consertar os sujeitos desviantes (delinquentes, infratores que cumprem medida socioeducativa de internação). Portanto, a socioeducação pode se afirmar como um dispositivo ao ultrapassar as fronteiras dos muros que "guardam pessoas".

Concluímos o artigo com a sugestão e demanda de estudos futuros que contemplem mais sujeitos de pesquisa que nos propomos a estudar. Além de escassas pesquisas a eles dirigidas, tanto na área de estudos organizacionais e/ou em outras ciências sociais, os espaços privativos de liberdade apresentam diferentes lacunas de investigação (políticas de segurança pública, ações direcionadas à contenção e/ou prevenção da criminalidade, redução da maioridade penal). Ademais, seria pertinente a replicação deste estudo a partir das histórias de vida de internos do Sistema Socioeducativo, de modo a permitir um comparativo com os resultados desse artigo e principalmente a investigação de outros dispositivos de poder, como classe social, raça, gênero, sexualidade, educação, trabalho, a partir das histórias de vida de (ex)internos do Sistema Socioeducativo e/ ou Sistema Prisional, voltadas especificamente para a realidade das prisões, dos sistemas socioeducativos, mas de outras regiões brasileiras.

\section{Agradecimentos}

Cumpre salientar que os autores agradecem ao editor da Revista Eletrônica de Ciência Administrativa (RECADM), bem como aos seus pareceristas, cujas recomendações e sugestões foram de grande valia para melhorias e desenvolvimento deste estudo. Agradecemos o apoio e incentivo da Fundação de Amparo à Pesquisa e Inovação do Espírito Santo - FAPES, pela oportunidade de execução desta pesquisa por meio do Processo $66610257 / 2014$.

\section{Referências}

Abrantes, P. A. (2012). Escola da vida. Tempo Social, revista de sociologia da USP, 24(2), 89-210.

Almeida, T. C., \& Mansano, S. R. V. (2012). Corpos marcados: uma análise histórica sobre a institucionalização de adolescentes em conflito com a lei. Mnemosine, 8(2), 61-183.

Baquero, R. V. A., Lemes, M. A., \& Santos, E. M. (2011). Histórias de vida de jovens egressos de medidas socioeducativas: entre a margem e a superação. Educação, 34(3), 341-350. 
Barros, V. A. (2005). A função política do trabalho e a ordem social. Veredas do Direito, 2(4), 51-66.

Barros, V.A., Barros, C. R., \& Faria, A. A. C. (2015). Une expérience de recueil d'histoires de vie dans l'univers carcéral au Brésil. Le sujet dans la cité, 1(4), 63-73.

Barros, V. A., \& Lopes, F. T. (2014). Considerações sobre a pesquisa em história de vida. In E. M. Souza (Org.). Metodologias e analíticas qualitativas em pesquisa organizacional (Vol. 1, pp. 41-64). Vitória: EDUFES.

Barros, V. A., \& Silva, L. R. (2002). A pesquisa em História de Vida. In I. Goulart (Org.). Psicologia organizacional e do trabalho: teoria, pesquisa e temas correlatos (pp.133-146). São Paulo: Casa do Psicólogo.

Brasil (2015). Levantamento Anual Sinase 2013. Secretaria de Direitos Humanos (SDH). Brasília: Secretaria de Direitos Humanos da Presidência da República.

Chauí, M. (1979). Os trabalhos da memória. In E. Bosi (Org.). Memória e sociedade: lembranças de velhos. São Paulo: Edusp.

Costa, S. G., \& Bratkowski, P. L. S. (2007). Paradoxos do trabalho prisional na era do capitalismo flexível: o caso do DETRAN-RS. Revista de Administração Contemporânea, 11(3), 127-147.

Creswell, J. W. (2003). O uso da teoria. In J. W. Creswell (Ed.). Projeto de Pesquisa: métodos qualitativos, quantitativos e mistos. Porto Alegre: Artmed.

Cruz, M.V.G., \& Batitucci, E.C. (2007). Homicídios no Brasil. Rio de Janeiro: Editora FGV.

Cruz, M. V. G., Souza, L. G., \& Batitucci, E. C. (2013, set/out). Percurso recente da política penitenciária no Brasil: o caso de São Paulo. Revista de Administração Pública, 47(5), 1307-1325.

Díaz, A.S. (2006). Uma aproximação à Pedagogia: educação social. Revista Lusófona de Educação, 1 (7), 91-114.

Espíndula, D. H. P, \& Santos, M. F. S. (2004). Representações sobre a adolescência a partir da ótica dos educadores sociais de adolescentes em conflito com a lei. Psicologia em Estudo, 9 (3), 357-367.

Fonseca, M. A. (2011). Michel Foucault e a constituição do sujeito. (3a ed.). São Paulo: EDUC.

Foucault, M. (1979). Microfísica do poder. (25a ed.). (R. Machado, Trad). Rio de Janeiro: Graal.

Foucault, M. (2003). Estratégia, poder-saber. Rio de Janeiro: Forense Universitária.

Foucault, M. (2004). Ética, sexualidade, política. Rio de Janeiro: Forense Universitária.

Foucault, M. (2010). O sujeito e o poder. In H. L. Dreyfus, \& P. Rabinow (Ed.). Michel Foucault, uma trajetória filosófica: para além do estruturalismo e da hermenêutica. Rio de Janeiro: Forense Universitária.

Foucault, M. (2012). Segurança, Penalidade e Prisão. (V. L. A. Ribeiro, Trad). Rio de Janeiro: Forense Universitária.

Foucault, M. (2013). Vigiar e punir: nascimento da prisão. (41.a ed.). (R. Ramalhete, Trad). Petrópolis: Vozes.

Franco, M. L. P. B. (2003). Análise de conteúdo. Brasília: Editora Plano. 
Garland, D. (2008). A cultura do controle: crime e ordem social na sociedade contemporânea. (A. Nascimento, Trad). Rio de Janeiro: Revan.

Gaulejac, V. (1991). La nevrose de classe. Paris: H\&G Editeurs.

Gomide, A. D., Nogueira, M. L. M., \& Barros, V. A. (2010). Histórias de vida e trabalho cultural: a construção do sujeito e a pertinência da memória. Cadernos CERU, 21,139-151.

Guralh, S. A. (2010). A socioeducação na dinâmica de afirmação dos Direitos da Criança e do adolescente no Brasil. Emancipação, 10 (1), 351-359.

Jesus, V. C. P. (2013). Condições escolares e laborais de adolescentes autores de atos infracionais: um desafio à socioeducação. Revista Eletrônica de Educação, 7 (3), 129-142.

Lei n. 8.069, de 13 de julho de 1990. (1990). Dispõe sobre o Estatuto da Criança e do Adolescente e dá outras providências. Brasília, 1990. Recuperado em 30 abril, 2016, de http://www.planalto.gov.br/ccivil_03/LEIS/L8069.htm

Lemos, F. C. S., Cardoso Junior, H. R., \& Alvarez, M. C. (2013). Instituições, confinamento e relações de poder: questões metodológicas no pensamento de Michel Foucault. Psicologia \& Sociedade, 26,100-106.

Lemos, A. M., Mazzilli, C. P., \& Klering, L. R. (1998). Análise do trabalho prisional: um estudo exploratório. Revista de Administração Contemporânea,129-149.

Lévy, A. (2000). Introduction. Revue Internationale de Psychosociologie. Récits de vie et histoire sociale, Paris, 6(14).

Maraschin, C., \& Raniere, E. (2011). Socioeducação e identidade: onde se utiliza Foucault e Varela para pensar o Sinase. Revista Katálysis, 14(1), 95-103.

Melossi, D. (2003). A new edition of Punishment and Social Structure thirty-five years later: a timely event. Social Justice, 30(1), 248-256.

Monte, F. F. C., \& Sampaio, L. R. (2012). Práticas Pedagógicas e Moralidade em Unidade de Internamento de Adolescentes Autores de Atos Infracionais. Psicologia: Reflexão e Crítica, 25(2), 368-377.

Monte, F. F. C., Sampaio, L. R., Rosa Filho, J. S., \& Barbosa, L. S. (2011). Adolescentes autores de atos infracionais: psicologia moral e legislação. Psicologia \& Sociedade,23(1), 125-134.

Nardi, H. C. (2006). Ética, trabalho e subjetividade. Porto Alegre: Editora da UFRGS.

Pavarini, M. (2010). A invenção penitenciária: a experiência dos Estados Unidos na primeira metade do século XIX. In D. Melossi, \& M. Pavarini. Cárcere e fábrica: as origens do sistema penitenciário (séculos XVI-XIX). (S. Lamarão, Trad). (2a. ed., pp.151-255). Rio de Janeiro: Revan.

Pires, F. M., \& Palassi, M. P. (2008). Frente de trabalho da iniciativa privada no sistema carcerário do Estado do Espírito Santo. Cadernos EBAPE.BR, 6(3), 1-16.

Silva, I. L., \& Guedes, O. S. (2011). A história oral das revoltas do centro de socioeducação de Londrina II: uma interpretação teórico-filosófica. Serviço Social \& Sociedade, 4(1), 48-73.

Silva, C. L. O., \& Saraiva, L. A. S. (2013). Lugares, discursos e subjetividades nas organizações: o caso de uma prisão. Cadernos EBAPE.BR, 11(3), 383-401. 
Souza, E. M. (2014, junho). Poder, diferença e subjetividade: a problematização do normal. Farol - Revista de Estudos Organizacionais e Sociedade, 1, 103-143.

Souza, E. M., \& Bianco, M. F. (2011). Subvertendo o desejo no teatro das organizações: problematizações contemporâneas sobre o desejo e a expansão da vida nas relações de trabalho. Caderno EBAPE.BR, 9(2), 394-411.

Souza, E. M.; Corvino, M. M. F.; \& Lopes, B. C. (2013). Uma análise dos estudos sobre o feminino e as mulheres na área de administração: a produção científica brasileira entre 2000 a 2010. Revista Organizações \& Sociedade, 20 (67), 603-621.

Souza, E. M., \& Costa, A. M. (2013). Usos e significados do conhecimento histórico em estudos organizacionais: uma (re)leitura do taylorismo sob a perspectiva do poder disciplinar. Cadernos EBAPE.BR, 11(1), 01-15.

Souza, E. M, Machado, L. D, \& Bianco, M. F. (2008). O homem e o pós-estruturalismo Foucaultiano: implicações nos estudos organizacionais. Revista Organizações \& Sociedade, 15(47), 71-86.

Souza, E. M., Petinelli-Souza, S., \& Leite-Da-Silva, A. R. (2013). O pós-estruturalismo e os estudos críticos de gestão: da busca pela emancipação à constituição do sujeito. Revista de Administração Contemporânea, 17(2), 198-217.

Souza, E. M., Leite-Da-Silva, A. R., \& Carrieri, A. P. (2012). Uma análise sobre as políticas de diversidade promovidas por bancos. Psicologia \& Sociedade, 24(2), 315326.

Wacquant, L. (2008). The Militarization of Urban Marginality: Lessons from the Brazilian Metropolis. International political sociology, 2, 56 -74.

Wacquant, L. (2011). As prisões da miséria. Rio de Janeiro: Zahar.

Wacquant, L. (2012). The Prison is an Outlaw Institution. Howard journal of criminal justice, 51, 1-15. 